\title{
Electro-oxidation of chlorophenols on powdered carbon electrodes of different porosity
}

\author{
Stanisław Biniak • Maciej Pakuła • \\ Andrzej Świątkowski • Krzysztof Kuśmierek • \\ Grzegorz Trykowski
}

Received: 10 June 2014/ Accepted: 16 October 2014/Published online: 31 October 2014

(C) The Author(s) 2014. This article is published with open access at Springerlink.com

\begin{abstract}
Activated carbons with large and medium-sized $S_{\mathrm{BET}}$, carbon blacks with different surface areas as well as graphite and heat-treated carbon of extremely low porosity were used in this study. Cyclic voltammograms were recorded for these materials in neutral electrolyte $\left(0.1 \mathrm{M} \mathrm{Na}_{2} \mathrm{SO}_{4}\right)$ solutions containing various chlorophenols (CPs; 4-chlorophenol, 2,4-dichlorophenol, 2,4,6-trichlorophenol) as depolarizers. The changes in the FTIR spectra of the electrode materials caused by the adsorption and/or coupling of CPs (and/or their degradation products) were recorded. HPLC was used for analyzing the concentration of CPs and their degradation products. The dependence of the electrochemical behavior of CPs with various chlorine contents on the character of carbon materials is discussed. The possible mechanism of the initial stages of CP degradation by electro-oxidation/ reduction depends on the kind of electrode material. Since different carbons vary in their electrochemical behavior and in their voltammetric response to the presence of different CPs, the application of the method for selecting electrode materials better suited to removing organochlorine impurities from ground-water seems feasible. The efficiency of the process depends closely on the kind of carbon and on the tendency for its surface to become covered by a polymeric (conducting or nonconducting) film of electro-degradation products.
\end{abstract}

\footnotetext{
S. Biniak $(\bowtie) \cdot$ G. Trykowski

Faculty of Chemistry, Nicolaus Copernicus University, ul. Gagarin 7, 87-100 Toruń, Poland

e-mail: sbiniak@chem.uni.torun.pl; sbiniak@chem.umk.pl
}

\section{Pakuła}

Faculty of Mechanical and Electrical Engineering, Naval University of Gdynia, 81-103 Gdynia, Poland

\section{A. Świątkowski · K. Kuśmierek}

Faculty of Advanced Technologies and Chemistry, Military University of Technology, 00-908 Warsaw, Poland 
Keywords Carbon electrodes $\cdot$ Adsorption $\cdot$ Chlorophenol $\cdot$ Porosity $\cdot$ FTIR

\section{Introduction}

The degradation of chlorophenols (CPs), which are common surface water pollutants, is an important environmental issue. Along with biodegradation and photodegradation processes [1], many electrochemical studies have been reported in recent years [1-16]. A wide variety of electrode materials, such as carbon black, CB [2], glassy carbon [3, $6,9]$, glassy carbon modified with aluminosilicates [4], graphite [5, 7, 8], Au [10, 15], diamond [16], boron-doped diamond [11, 13] and Pt [12, 14] have been used for the electro-oxidative removal of CPs. In addition, the electro-polymerization behavior of CPs during voltammetric measurements (electrode fouling) has been reported, as has the fact that the tars formed display a low rate of oxidation, low permeability and strong adhesion to the electrode [14-17]. Electrode fouling is more likely to occur in the potential range of water stability, but fouling is less of a problem in the oxygen evolution region, probably due to oxygen bubbles attacking the polymeric films and to the oxidative destruction of these films [18]. Many new modified electrode materials $[4,13]$ have been developed to minimize the fouling effect. Electrochemical processes are accompanied by the adsorption of organics on electrode materials, especially when these are highly porous $[2,8]$. Reaction mechanisms have been postulated in some papers $[1,2,7,9,12-14]$. Depending on the kind of electrode materials, different intermediate and final products of redox processes are obtained. Electrochemical degradation involves the cathodic reduction or the anodic oxidation of CPs. There are three possible mechanisms for their reduction to phenols: direct reduction at the cathode, hydrogenation (reduction by evolved hydrogen) and adsorption of CP at the cathode surface followed by hydrogenation [8, 19-22]. Several mechanisms of anodic oxidation have been postulated $[2,4,7]$. Generally speaking, it is suggested that CP radicals are first formed and subsequently deprotonated. The products undergo further oxidation to benzoquinone, hydroquinone and catechol derivatives. It is these intermediates that are the starting materials for the synthesis of polyoxyphenylenes by the oxidative displacement of chlorine. These polymeric products are responsible for the above mentioned fouling of the electrode surface. Investigations of the electrochemical behavior of these systems are usually limited by using flat electrodes, basic or acidic electrolyte solutions; sorption and electrosorption effects are often not taken into consideration at all.

The aim of the present work is to describe and compare the influence of the porosity and specific surface area of carbon electrode materials on the oxidation and reduction of organochlorine compounds diluted in aqueous solution. In this study, cyclic voltammetric (CV) investigations were performed using neutral aqueous solutions of three different CPs [4-chlorophenol (4-CP), 2,4-dichlorophenol (2,4-DCP) and 2,4,6-trichlorophenol (2,4,6-TCP)] in $0.1 \mathrm{M}$ $\mathrm{Na}_{2} \mathrm{SO}_{4}$. Several powdered carbons of different porosity: two activated carbons (ACs), graphitized $\mathrm{CBs}$ and powdered graphite were used as electrode materials. 


\section{Experimental section}

\section{Materials}

Samples of ash-free ACs with large (R3ex, Norit, deashed with conc. HF and HC) and medium-sized (L2S, CECA) specific surface areas (denoted as AC-1 and AC-2, respectively); two graphitized CBs (Carbopack B and Carbopack C, Supelco) with tenfold different surface areas (CB-B and CB-C) as well as graphite (SigmaAldrich, G-SA) and AC of extremely low porosity subjected to high-temperature treatment $\left(2,700{ }^{\circ} \mathrm{C}\right.$, AC-HT) were used as sorbents and electrode materials. Granules of ACs (AC-1, AC-2 and AC-HT) were milled and grains of size 0.075-0.060 $\mathrm{mm}$ were sieved. CBs and graphite were used as received.

The carbon materials were characterized texturally by means of $\mathrm{N}_{2}$ lowtemperature adsorption measurements on a Micromeritics ASAP 2010 volumetric adsorption analyzer (Norcross, GA, USA). An energy dispersive X-ray analysis system (Quantax 200, Bruker-AXS Microanalysis) integrated with a scanning electron microscope (LEO 1430VP) was used to estimate the total oxygen bond to the carbon surface. Six different surface sites $\left(0.2 \mathrm{~cm}^{2}\right)$ were analyzed for each material.

The adsorbates and depolarizers (in the electrochemical studies), i.e. three CPs: 4-CP, 2,4-DCP and 2,4,6-TCP, were purchased from Sigma-Aldrich.

\section{Adsorption of CPs}

CPs (4-CP, 2,4-DCP, 2,4,6-TCP) were adsorbed on the carbon samples (50 $\mathrm{mg}$ ) at $20{ }^{\circ} \mathrm{C}$ from aqueous electrolyte solutions $\left(50 \mathrm{~cm}^{3} 0.1 \mathrm{M} \mathrm{Na}_{2} \mathrm{SO}_{4}\right)$ containing various concentrations of adsorbate: $2 \mathrm{mM}$ (4-CP, 2,4-DCP) or $0.5 \mathrm{mM}(2,4,6-$ TCP). The initial and final (after $6 \mathrm{~h}$ of shaking) concentration of CPs were measured by HPLC (DAD, Shimadzu LC-20, Kyoto, Japan). The analytes were separated on a Phenomenex Luna $\mathrm{C}_{18}(4.6 \times 150 \mathrm{~mm}, 3 \mu \mathrm{m})$ column (Torrance, CA, USA). The chromatographic measurements were carried out under isocratic conditions on a Luna $\mathrm{C}_{18}(4.6 \times 150 \mathrm{~mm}, 3 \mu \mathrm{m})$ column operated at $313 \mathrm{~K}$ with methanol and water adjusted to $\mathrm{pH} 3.0$ with acetic acid (80:20, v/v). The mobile phase was pumped at a flow rate of $0.6 \mathrm{ml} \mathrm{min}^{-1}$, and peaks were monitored at $281 \mathrm{~nm}$.

\section{Cyclic voltammetry}

The cyclic voltammetry measurements were done with an Autolab (Eco Chemie) modular electrochemical system equipped with a PGSTAT 10 potentiostat driven by GPES 4.9 software, and a typical three-electrode electrochemical cell similar to the one described in one of our earlier papers [23, 24]. The working, counter and reference electrodes were a powdered carbon electrode, a Pt wire and a saturated calomel electrode (SCE), respectively. The working electrode design was the same as that used and described earlier [23]. After vacuum desorption $\left(10^{-2} \mathrm{~Pa}\right)$, the powdered sample (mass $100 \mathrm{mg}$ ) was placed in an electrode container (with a $\mathrm{Pt}$ 
plate as contact) and drenched with a de-aerated $0.1 \mathrm{M} \mathrm{Na}_{2} \mathrm{SO}_{4}\left(100 \mathrm{~cm}^{3}\right)$ solution (without or with depolarizer) to obtain a $3-5 \mathrm{~mm}$ sedimentation layer. After assembly, the electrochemical cell was de-aerated until the potentiometric response of the working electrode had stabilized. Cyclization was then carried out and CV curves recorded with a $1 \mathrm{mV} \mathrm{s}^{-1}$ sweep rate, always starting from zero in the direction of positive potentials. All CV measurements were done between -0.4 and 1.2 V versus SCE potential range. Some of the CV experiments were repeated three times with fresh samples of electrode materials; excellent conformity of curve shapes and current values (differences $<3 \%$ ) was obtained. After the voltammetric cyclizations the concentration of the products of $\mathrm{CP}$ electrochemical degradation were determined by HPLC, as described above.

\section{Infrared spectroscopy}

FTIR spectra of the carbon samples initially and after use as electrode materials, were obtained with a Perkin-Elmer FT-IR Spectrum 2000 spectrometer. The carbon-KBr mixtures (1.5:300) were ground, then desorbed at room temperature and pressed to obtain IR-transparent pellets. Following electrochemical action, the samples were rinsed in water, dried and desorbed under vacuum at $110{ }^{\circ} \mathrm{C}$.

\section{Results and discussion}

ACs, CBs, graphite and high-temperature treated carbon, were selected as materials with strongly differentiated porous structures. Their specific surface areas $\left(S_{\mathrm{BET}}\right)$, determined using low-temperature $\mathrm{N}_{2}$ adsorption isotherms, are listed in Table 1 . The total surface oxygen content (from EDS measurements) and the electrical double layer pseudo-capacity $\left(C_{\mathrm{dl}}\right)$ determined for potentials $0.0 \mathrm{~V}$ versus SCE from cyclic voltammograms obtained for carbon electrodes in blank electrolyte also given in Table 1. The differences in the electrical double layer pseudo-capacity are correlated with surface area, but they are disturbed by the presence of surface oxygen. CV investigations of the CPs were performed using all these materials as powdered working electrodes in the typical three-electrode system cell [23]. A $0.1 \mathrm{M}$ solution of $\mathrm{Na}_{2} \mathrm{SO}_{4}$ was used as electrolyte. Near-neutral $\mathrm{pH}$ values are typical of surface and ground waters containing organic contaminants. The changes in depolarizer concentrations were recorded using HPLC [25]. A drop in depolarizer concentration can be caused by an electrochemical reaction and/or adsorption on electrode material. The carbon materials used exhibited huge differences in porosity (Table 1): from high-porous ACs $\left(S_{\mathrm{BET}}>900 \mathrm{~m}^{2} \mathrm{~g}^{-1}\right)$, through porous CB $\left(S_{\mathrm{BET}}\right.$ near $\left.100 \mathrm{~m}^{2} \mathrm{~g}^{-1}\right)$ to low-porous materials $\left(S_{\mathrm{BET}} \leq 10 \mathrm{~m}^{2} \mathrm{~g}^{-1}\right)$. The porous carbon materials were differentiated by taking their pore size distribution into account: (i) AC-1 is mainly microporous (only a small amount of mesopores $2-3 \mathrm{~nm}$ ), (ii) AC-2 contains similar volumes of micro- and mesopores (width 2-20 nm), (iii) CBB contains mainly mesopores (width $15-65 \mathrm{~nm}$ ).

The adsorption capacity towards CPs dissolved in blank electrolyte (concentration as in CV measurements) was thus determined independently for the first three 
Table 1 Parameters characterizing surface properties of carbon materials

\begin{tabular}{lclllc}
\hline Samples & $S_{\mathrm{BET}}\left(\mathrm{m}^{2} \mathrm{~g}^{-1}\right)$ & $\mathrm{V}_{\mathrm{mi}}\left(\mathrm{cm}^{3} \mathrm{~g}^{-1}\right)$ & $\mathrm{V}_{\mathrm{me}}\left(\mathrm{cm}^{3} \mathrm{~g}^{-1}\right)$ & $\mathrm{O}^{\mathrm{a}}(\mathrm{at} . \%)$ & $C_{\mathrm{dl}}^{\mathrm{b}}\left(\mathrm{F} \mathrm{g}^{-1}\right)$ \\
\hline AC-1 & 1,390 & 0.461 & 0.081 & 3.8 & 13.0 \\
$\mathrm{AC}-2$ & 925 & 0.245 & 0.235 & 5.3 & 8.0 \\
CB-B & 98 & 0.075 & 0.508 & 3.0 & 10.2 \\
CB-C & 10 & - & - & 2.5 & 1.2 \\
G- SA & 10 & - & - & 2.3 & 0.6 \\
AC-1-HT & 8 & - & - & 2.0 & 1.4 \\
\hline
\end{tabular}

${ }^{\text {a }}$ From EDS

${ }^{\mathrm{b}}$ In blank solution $\left(0.1 \mathrm{M} \mathrm{Na}_{2} \mathrm{SO}_{4}\right)$ for $0.0 \mathrm{~V}$ versus $\mathrm{SCE}$

Table 2 Parameters characterizing sorption capacity carbon materials towards chlorophenols $(A$, mmol $\left.\mathrm{g}^{-1}\right)$, the reduction in their concentration as a result of electrochemical cyclization $\left(U, \mathrm{mmol} \mathrm{g}^{-1}\right)$ and the quantity of $\mathrm{Cl}$-containing soluble products in electrolyte solution after cyclization $\left(P, \mathrm{mmol} \mathrm{g}^{-1}\right)$

\begin{tabular}{|c|c|c|c|c|c|c|c|c|c|}
\hline \multirow[t]{3}{*}{ Samples } & \multicolumn{9}{|c|}{ Depolarizer, concentration } \\
\hline & \multicolumn{2}{|c|}{ 4-CP, $2 \mathrm{mM}$} & \multicolumn{3}{|c|}{ 2,4-DCP, $2 \mathrm{mM}$} & \multicolumn{4}{|c|}{ 2,4,6-TCP, $0.5 \mathrm{mM}$} \\
\hline & $A$ & $U$ & $A$ & $U$ & $P_{1} 4-\mathrm{CP}$ & $A$ & $U$ & $P_{2} 2,4-\mathrm{DCP}$ & $P_{1} 4-\mathrm{CP}$ \\
\hline AC-1 & 1.39 & 1.15 & 1.50 & 1.18 & 0.07 & 0.39 & 0.29 & 0.033 & 0.042 \\
\hline AC-2 & 1.72 & 0.88 & 1.88 & 0.77 & 0.05 & 0.50 & 0.17 & 0.091 & 0.042 \\
\hline CB-B & 0.15 & 0.92 & 0.22 & 0.98 & 0.06 & 0.07 & 0.25 & 0.084 & 0.075 \\
\hline $\mathrm{CB}-\mathrm{C}$ & - & 0.23 & - & 0.38 & 0.08 & - & 0.25 & 0.07 & 0.023 \\
\hline G-SA & - & 0.34 & - & 0.64 & 0.11 & - & 0.24 & 0.07 & 0.013 \\
\hline AC-1-HT & - & 0.35 & - & 0.53 & 0.05 & - & 0.16 & 0.074 & 0.072 \\
\hline
\end{tabular}

materials with larger surface areas (AC-1, AC-2, CB-B). Table 2 compares the uptake of depolarizer $\left(U, \mathrm{mmol} \mathrm{g}^{-1}\right)$ on electrode materials (calculated from the decrease in depolarizer concentration in solution) with the adsorption capacity (of the above materials, $A, \mathrm{mmol} \mathrm{g}^{-1}$ ) and the sum of the amounts of Cl-containing products (in electrolyte solution after cyclization) related to the mass of electrode material $\left(P, \mathrm{mmol} \mathrm{g}^{-1}\right)$. Trace amounts of other non-chlorine-containing products (this depends on the electrode materials) were also noted in solution after cyclization (Fig. 4). According to literature data [26], the adsorption capacity (Table 2) generally increases with the number of chlorine atoms in sorbent molecules, but with respect to particular CPs depends on the porous structure, surface area, electronic properties and surface chemistry of the carbon materials [27].

The results of $\mathrm{CV}$ investigations for the carbon electrode materials are listed as six sets of voltammograms (Figs. 1, 2, 3). Each set shows the voltammograms recorded in 4-CP, 2,4-DCP or 2,4,6-TCP containing blank electrolyte solution $\left(0.1 \mathrm{M} \mathrm{Na}_{2} \mathrm{SO}_{4}\right)$. Additionally, the steady-state $\mathrm{CV}$ curves for the initial carbon materials in blank solution (without depolarizer) are presented (dashed lines, No. 4). 
(a)

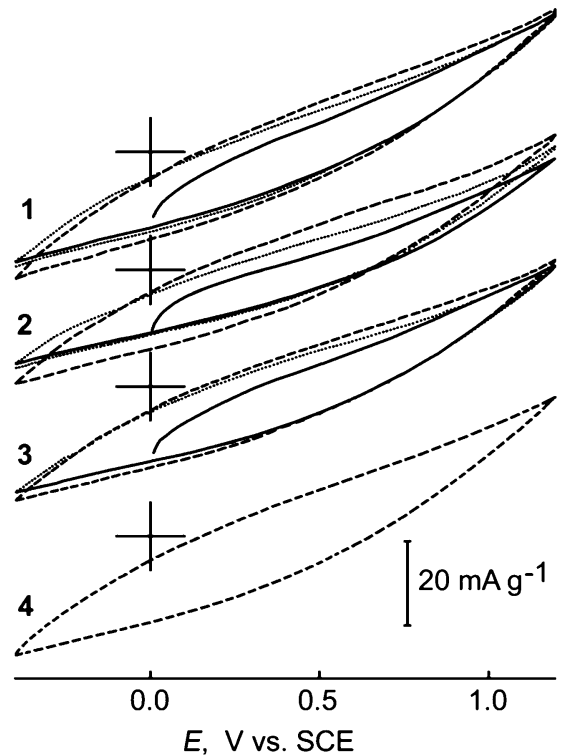

(b)
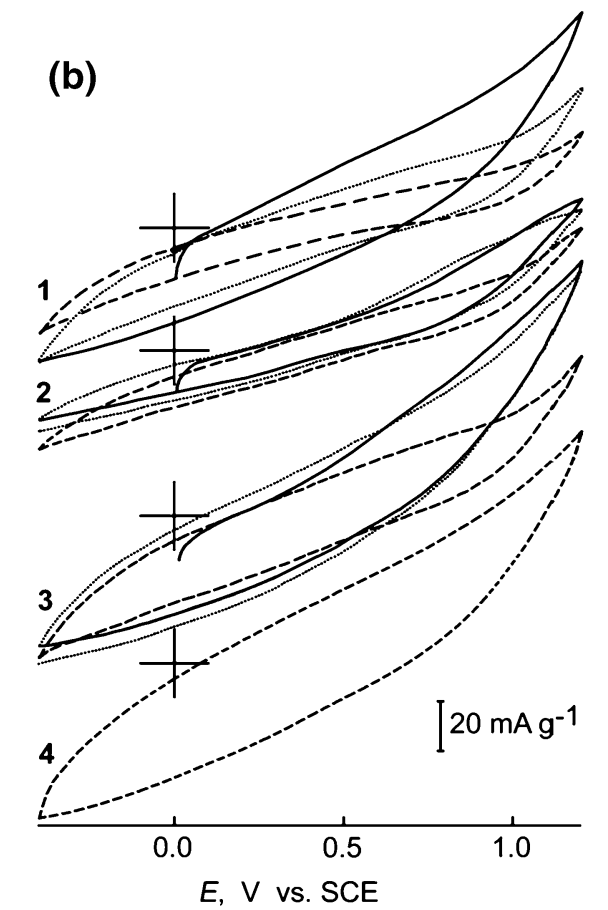

$E, V$ vs. SCE

Fig. $1 \mathrm{CV}$ s of activated carbon $\mathrm{AC}-1$ (a) and $\mathrm{AC}-2$ (b) powdered electrodes in $0.1 \mathrm{M} \mathrm{Na}_{2} \mathrm{SO}_{4}$ containing: $2 \mathrm{mM}$ 4-CP (1), $2 \mathrm{mM}$ 2,4-DCP (2), $0.5 \mathrm{mM} \mathrm{2,4,6-TCP} \mathrm{(3)} \mathrm{and} \mathrm{in} \mathrm{blank} \mathrm{solution} \mathrm{for}$ comparison (4). First cycle: solid line, second cycle: dotted line, steady state currents: dashed line, $\mathrm{v}=1 \mathrm{mV} \mathrm{s}^{-1}$

The shapes of the voltammograms show that there were three different kinds of electrochemical behavior: (i) high-porous AC with dominant pseudo-capacitive currents which mask faradaic reactions (Fig. 1a and 1b), (ii) $\mathrm{CB}$ with an intermediate surface area (CB-B) with quasi-reversible Faradaic processes (Fig. 2a), (iii) low-porous carbon materials, with the lowest (nearly tenfold) pseudo-capacity current and with distinct faradaic processes (Figs. 2b, 3a, b).

The electrical resistance of a packed bed of AC particles observed on CV curves (Fig. 1), is a function of the contact resistance between the particles (major fraction) and the intra-particle resistance. AC is a composite of amorphous and microcrystalline substructures and exhibits semiconducting properties. The conduction processes are complicated because the current carriers in carbon material are assumed to be localized by disorder, which introduces randomness into the potential-energy bands for electrons. Carbons produced/treated at high temperatures become structurally more ordered (enhanced crystallinity, reduced distance between graphene layers), which results in a lowering of sample resistivity [28]. Because surface oxygen also affects the carbon resistivity and the adsorption efficiency of CPs, a given carbon sample contains a small and relatively similar amount of oxygen (no oxidative modification). 
(a)

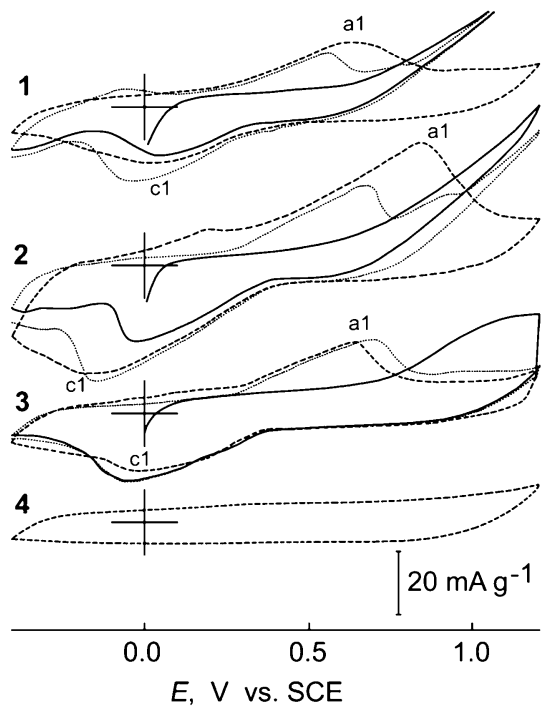

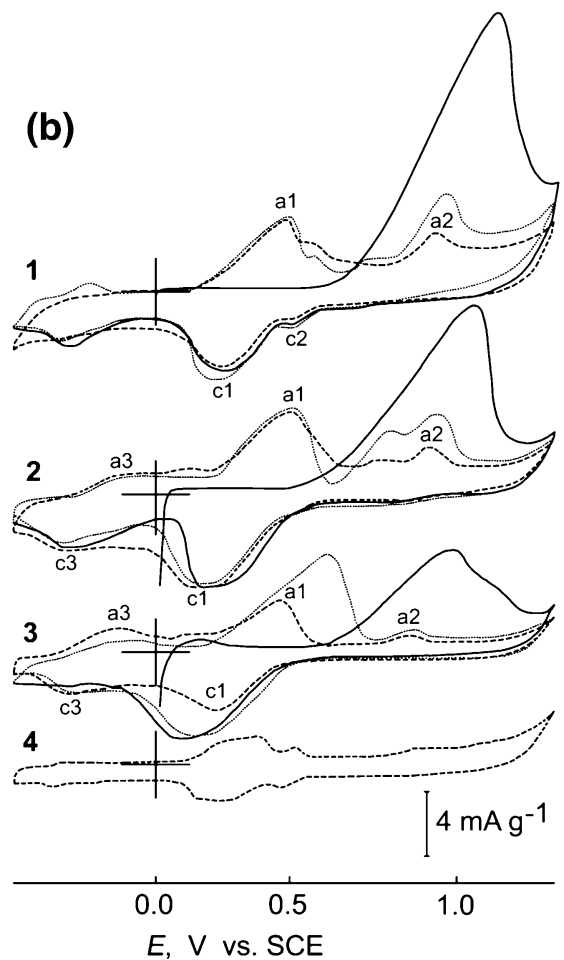

Fig. $2 \mathrm{CVs}$ of carbon blacks $\mathrm{CB}-\mathrm{B}$ (a) and $\mathrm{CB}-\mathrm{C}$ (b) powdered electrodes (line descriptions as for Fig. 1)

Chromatographic analysis of the products of the electrochemical processes, present in solutions of particular CPs (Fig. 4a-4c), shows that the variety in their composition depends on the electrode carbon material. Electrochemical degradation of 4-CP caused by voltammetric cyclization yields phenol (peak $\delta$ ) and quinones (peak $\rho$ ) as the main products in solution (Fig. 4a). Especially large amounts are produced with high-porous materials (ACs), which become smaller as the electrode material surface area decreases. Electrochemical degradation of 2,4-DCP (Fig. 4b) leads to the formation of different amounts of 4-CP (peak $\alpha$ ) and its isomers (doubly overlapping peaks) as well as small amounts of quinones (peak $\rho$ ). 2,4-DCP (peak $\beta$ ) and 4-CP (peak $\alpha$ ) plus trace amounts of non-chlorine compounds are present in 2,4,6-TCP solution after voltammetric cyclization (Fig. 4c).

FTIR spectra of the electrode materials were recorded (Fig. 5) following adsorption (on porous materials: $\mathrm{AC}-1, \mathrm{AC}-2$ and $\mathrm{CB}-\mathrm{B}$ ) and voltammetric cyclization in neutral $\left(0.1 \mathrm{M} \mathrm{Na} \mathrm{SO}_{4}\right)$ electrolyte solution containing CPs as depolarizers (with all the carbons tested). Comparison of these spectra obtained for the initial carbons (4) revealed both similarities and differences in their shapes following electrochemical action (spectra 1-3) and adsorption (spectra $1^{\prime}-3^{\prime}$ ) for particular $\mathrm{CP}$ solutions. All the spectra showed a band of stretching $\mathrm{OH}$ vibrations (near $3,430 \mathrm{~cm}^{-1}$ ) due to carbon surface hydroxyl groups and chemisorbed water. 
(a)

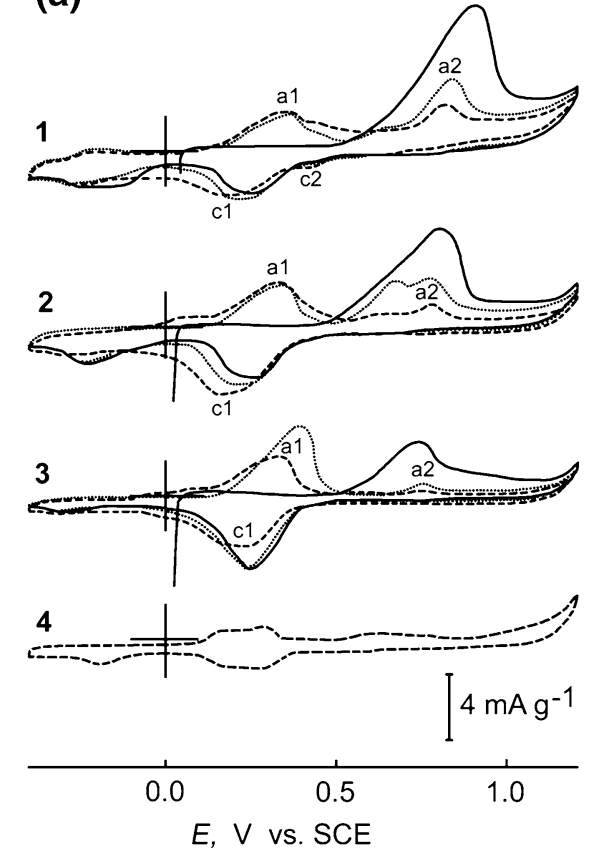

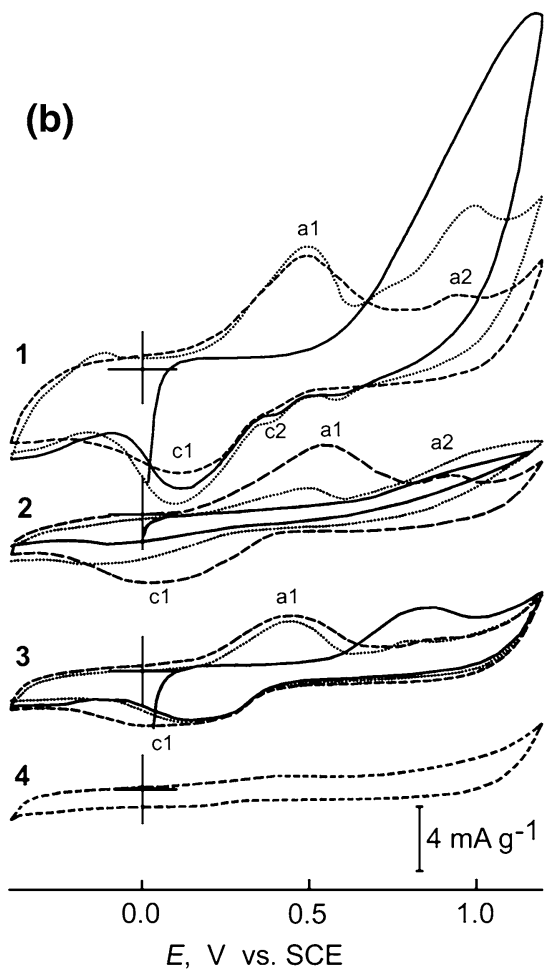

Fig. 3 CVs of graphite G-SA (a) and heat-treated activated carbon AC-1-HT (b) powdered electrodes (line descriptions as for Fig. 1)

This band is omitted from the spectra for better clarity of the spectral changes. Below 2,000 $\mathrm{cm}^{-1}$, the carbon material spectra displayed absorption typical of surface and structural oxygen species (functional groups and inactive oxygen bridges incorporated into the solid matrix) as well as absorption of skeletal carbon bonds. The presence of partially overlapping bands near $1,630 \mathrm{~cm}^{-1}$ and at $1,560 \mathrm{~cm}^{-1}$ can be respectively attributed to stretching vibrations of aromatic carbon $(>\mathrm{C}=\mathrm{C}<$ ) and $>\mathrm{C}=\mathrm{O}$ moieties in quinone and/or conjugated systems like diketone, keto-esters and keto-enol structures. The complicated nature of the adsorption bands in the $1,650-1,500 \mathrm{~cm}^{-1}$ region suggests that aromatic ring bands and double bond $(\mathrm{C}=\mathrm{C})$ vibrations overlap the afore-mentioned $\mathrm{C}=\mathrm{O}$ stretching vibration bands and $\mathrm{OH}$ binding vibration bands. Another broad band in the $1,470-1,380 \mathrm{~cm}^{-1}$ range consists of a series of overlapping absorption bands ascribable to the deformation vibration of surface hydroxyl groups and in-plane vibrations of $\mathrm{C}-\mathrm{H}$ in various $\mathrm{C}=\mathrm{C}-\mathrm{H}$ structures. The partially resolved peaks forming the absorption band in the $1,250-900 \mathrm{~cm}^{-1}$ region can be assigned to etherlike (symmetrical stretching vibrations) and phenolic structures (vibrations near $1,200 \mathrm{~cm}^{-1}$ ) existing in different structural environments. The relative intensity of 
Fig. 4 Chromatograms obtained from an aqueous standard solution (7) of chlorophenols: a $2 \mathrm{mM} 4-\mathrm{CP}$ (peak $\alpha$ ), b 2 mM 2,4-DCP (peak $\beta$ ), c $0.5 \mathrm{mM} \mathrm{2,4,6-TCP}$ (peak $\gamma$ ) after electrochemical cyclization on powdered carbon electrodes: (1) AC-1, (2) AC-2, (3) CB-B, (4) CB-C, (5) G-SA, (6) AC-1-HT. Peaks of nonchlorine containing products: $\delta$ phenol, $\rho$ quinones (overlapping hydroquinone, benzoquinone and catechol peaks)

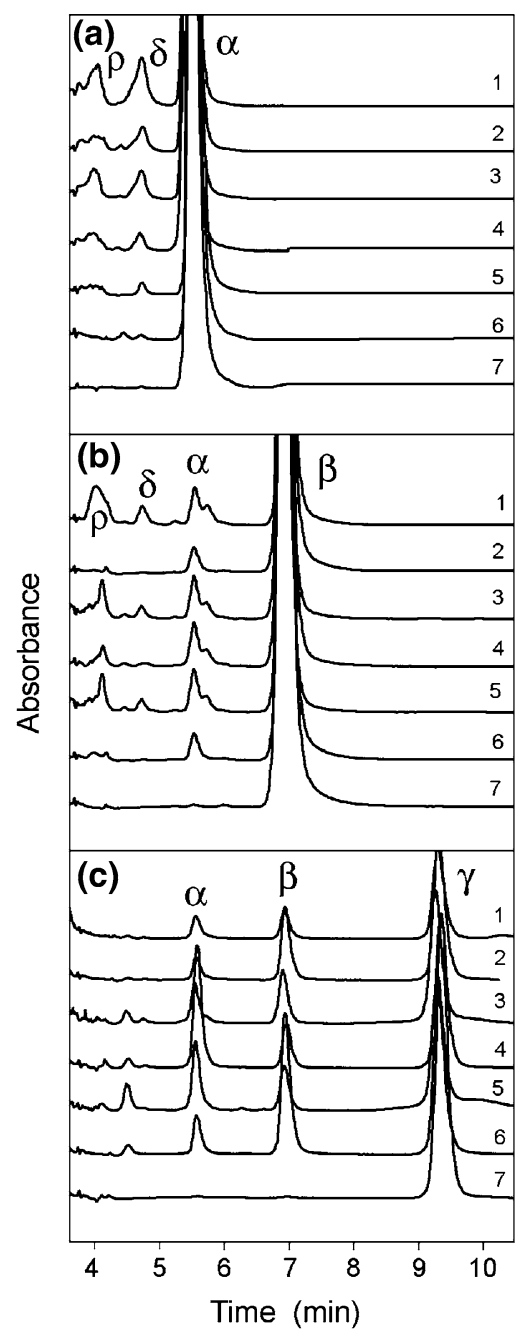

all these bands depends on the kind of carbon material and its "fingerprint". The ACs exhibited relatively tall bands ascribable to $>\mathrm{C}=\mathrm{O}$ and $>\mathrm{C}-\mathrm{O}-\mathrm{C}<$ moieties (Fig. 5a and 5b). For the CBs there is a dominant band of aromatic carbon with the presence of $>\mathrm{C}=\mathrm{O}$ structures (Fig. $5 \mathrm{c}$ and $5 \mathrm{~d}$ ) and a relatively small absorption band formed by overlapping peaks in the $1,300-950 \mathrm{~cm}^{-1}$ region, while for the hightemperature treated materials (Fig. 5e and 5f) only aromatic carbon and oxygen bridges $(>\mathrm{C}-\mathrm{O}-\mathrm{C}<)$ are seen.

The FTIR spectral changes following $\mathrm{CP}$ adsorption on porous materials AC-1 (Fig. 5a), AC-2 (Fig. 5b) and CB-B (Fig. 5c) were negligible (the spectra marked $1^{\prime}, 2^{\prime}$ and $3^{\prime}$ after the adsorption of 4-CP, 2,4-DCP and 2,4,6-TCP). The small changes in the relative intensity of the main peaks and the appearance of small 
(a)

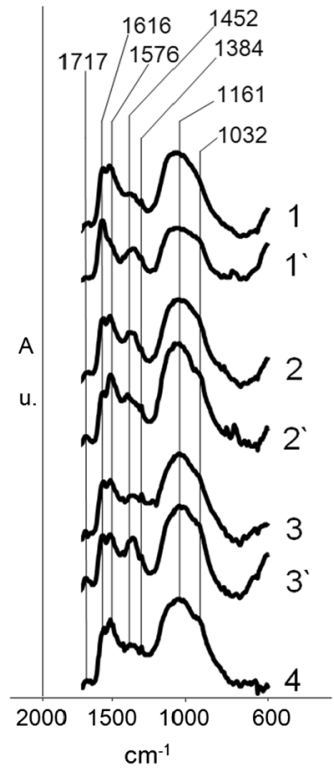

(d)

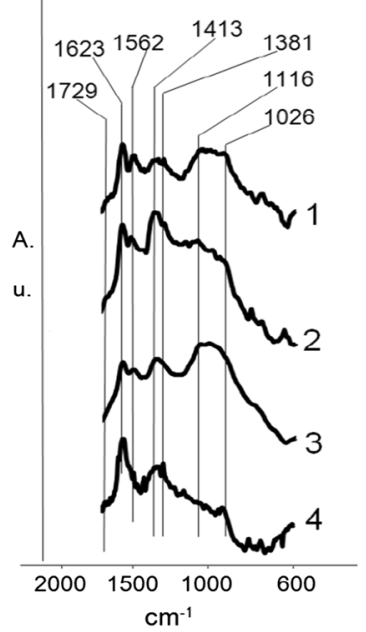

(b)

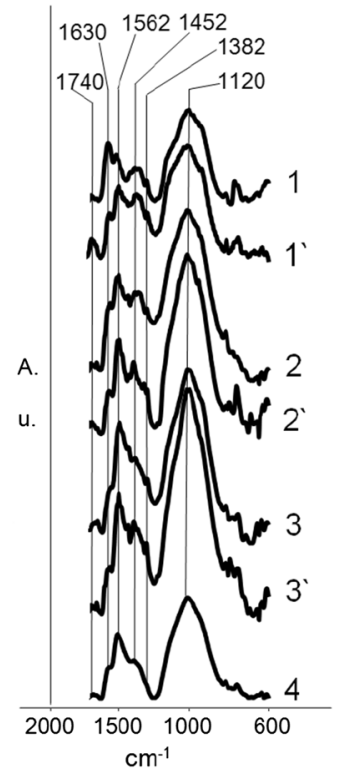

(e)

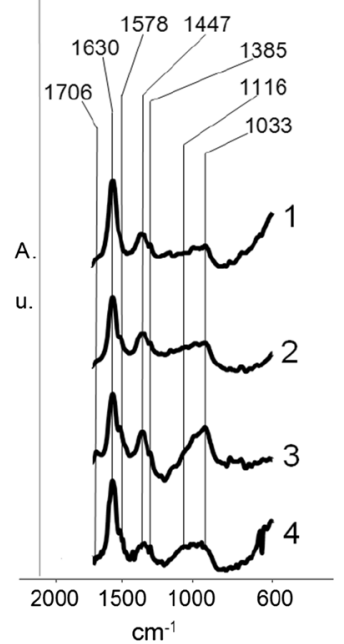

(c)

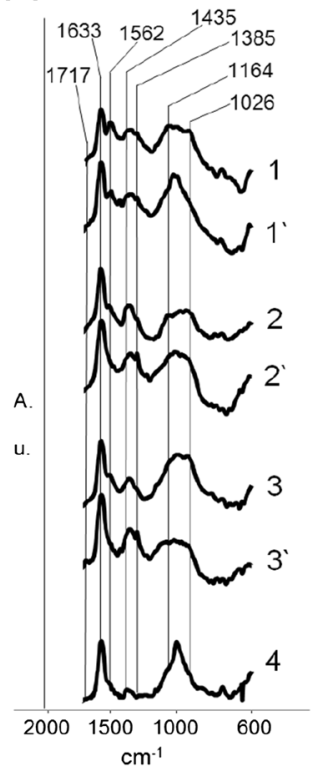

(f)

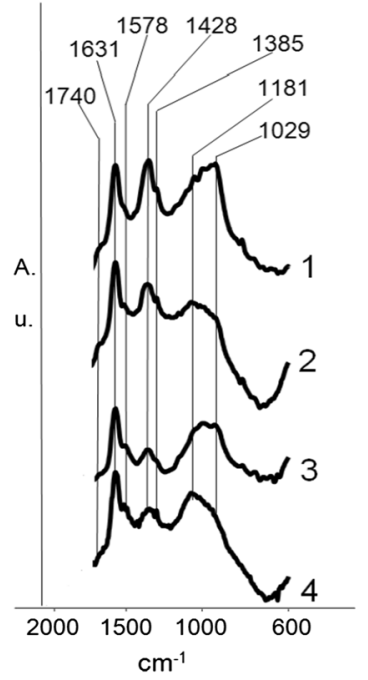

Fig. 5 FTIR spectra of activated carbons AC-1 (a) and AC-2 (b), carbon blacks CB-B (c) and CB-C (d), powdered graphite G-SA (e) and heat-treated activated carbon AC-1-HT (f) after electrochemical cyclization (1-3) and adsorption $\left(1^{\prime}-3^{\prime}\right)$ from electrolyte solutions containing 4-CP $\left(1,1^{\prime}\right), 2$,4-DCP $(2$, $\left.2^{\prime}\right), 2,4,6-\mathrm{TCP}\left(3,3^{\prime}\right)$ as well as the spectra of the initial samples (4)

narrow peaks (e.g., near 1500, 1380, $1300 \mathrm{~cm}^{-1}$ and in the $880-700 \mathrm{~cm}^{-1}$ region) due to physically sorbed CPs depend on the type of carbon materials, its surface chemistry and kind of sorbate used [29, 30]. 
The ACs (AC-1 and AC-2) capable of adsorbing large amounts of CPs (Table 2) exhibited negligible changes in their electric double layer $(e d l)$ capacities during potential cyclization (Fig. 1). Moreover, electrosorbed ions of the blank electrolyte removed adsorbed CP molecules from the carbon surface, especially in sample AC-2 (see the values of $A$ and $U$ in Table 1). On the other hand, a large decrease in CP concentration took place as a result of electrochemical action with sample CB-B, which had lower adsorption ability and a high $e d l$ capacity. At the same time, the shape of the CV curves for the CB-B electrodes (Fig. 2a) indicated on the presence of a large faradaic current of a quasi-reversible couple (quinone-hydroquinone-like system). After cyclization, several products of electrochemical degradation were recorded in electrolyte solution (Fig. 4). Their amounts and relative proportion depend on the kind of carbon materials and show the sample AC-2 (curves 2 in Fig. 4a-4c) to have a lower electrochemical activity. Additional surface coverage by $\mathrm{CP}$ molecules probably leads to the observed decrease in the $e d l$ capacity of the AC-2 electrode (see Fig. 1a). The spectral changes for porous carbons samples (Fig. 5a-5c for AC-1, AC-2 and CB-C), i.e., the relative increase of bands near $1,620 \mathrm{~cm}^{-1}(>\mathrm{C}=\mathrm{O})$ and $1,440 \mathrm{~cm}^{-1}(>\mathrm{OH})$, can be attributed to the presence of quinone-hydroquinone systems on the carbon surface. The increase in these bands is pronounced in sample CB-C, but less so in samples AC-1 and AC-2.

On the other hand, quite similar spectral changes were observed for non-porous samples without CP adsorption (see Fig. 5d-5f). The spectral changes caused by the electrodegradation of CPs during voltammetric cyclization, i.e., a marked increase in the relative intensity of the $1,630 \mathrm{~cm}^{-1}$ (quinone-like moieties) and $1,440 \mathrm{~cm}^{-1}$ bands (hydroxyl moieties) as well as the overlapping bands in the 1,250-950 $\mathrm{cm}^{-1}$ region (carboxylic-phenol esters), may indicate cleavage of CPs and/or quinone rings on the surface as a consequence of the electrochemisorption of CPs and electrodegraded molecules as well as the partial electrochemical ionization and oxidation of chemisorbed species [4, 9, 29]. Electrodegradation products are present in electrolyte solution after cyclization (Fig. 4a-4c, curves 4-6).

The shape of the cyclic voltammograms for electrodes from non-porous materials are similar (for particular CPs) and indicate the presence of several anodic and cathodic peaks attributed to redox processes. The steady state peak potentials and currents for 4-CP, 2,4DCP and 2,4,6-TCP are listed in Table 3. During the electrochemical cyclization of 4-CP (curves 1 in Figs. 2b and 3) there was an anodic peak (a2), strong in the first cycle but decreasing rapidly in the next one (with a drop in peak potential from 1,050 to $840 \mathrm{mV}$ vs. SCE). The other CPs behaved in a similar manner but with different peak potentials. According to the literature $[9,31-34]$, these peaks can be attributed to reaction 1 :

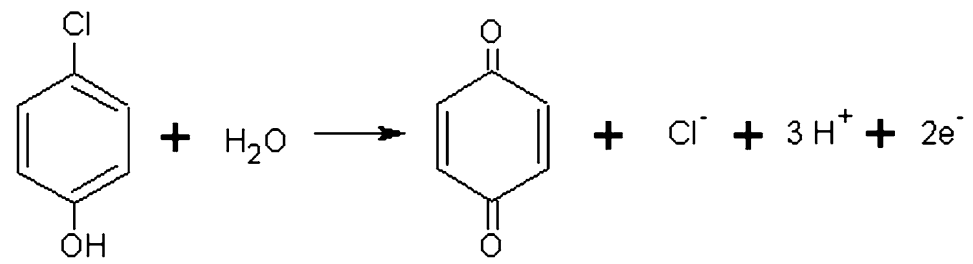


Next, the cathodic part of the voltammograms exhibited some reduction peaks of adsorbed quinones (or chloroquinones) and CPs. They are ascribable to the following possible reactions: quinone-hydroquinone redox couple (2) and $\mathrm{CP}$ reduction (3).<smiles>O=C1C=CC(=O)C=C1</smiles>

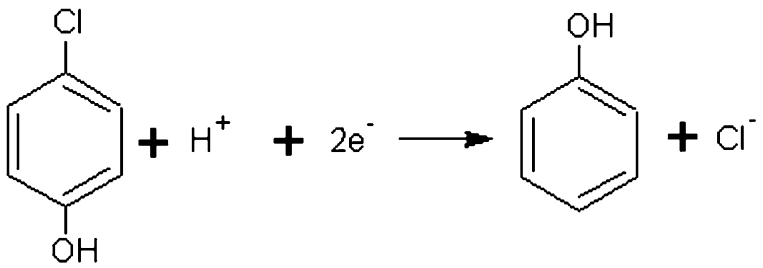

The oxidative electrosorption of these systems is responsible for the presence of additional absorption peaks, due to $\mathrm{C}=\mathrm{O}$ and $\mathrm{C}-\mathrm{OH}$ structural moieties (quinone/ hydroquinone couple), on the FTIR spectra of the carbon electrodes (CB-C, G-SA and $\mathrm{AC}-\mathrm{HT}$ ). A similar process, the electrooxidation and electroreduction of CPs adsorbed on various carbon electrodes has been described and explained in a similar manner $[2,7,9,12]$. As a result of the voltammetric cyclization of CPs, degradation products block the surface of ACs, which leads to a decrease their adsorption capacity, especially in sample AC-2 (Table 2). This is accompanied by a lowering of the pseudocapacitive currents of carbon electrodes, weak in sample AC-1 and marked in AC-2 (Fig. 1, dashed lines). This may be the result of differences in pore size distribution in these carbons (Table 1). This is confirmed by the observed dissolution (desorption) of some of the degradation products from sample AC-2 (Fig. 4). For carbon black CB-B, despite its relatively small adsorption, there is a marked decrease in $\mathrm{CP}$ concentrations in electrolyte solution after voltammetric cyclization (Table 2). Electrochemically active degradation products are present both on the surface (Fig. 2a) and in electrolyte solution (Fig. 4; Table 2). Carbon materials with poorly-developed porosity (CB-C, G-SA, AC-1-HT) are less able to undergo electrochemical degradation probably because of their small adsorption capacity. Owing to the absence of capacitive currents, the course of electrochemical degradation can then be tracked. The two stages of 2,4-DCP degradation visualized by two anodic peaks (separate or overlapping) are seen on the CVs recorded for these samples (Figs. 2 and 3).

Depending on the kind of $\mathrm{CP}$, the electrochemical processes proceed in different ways. Degradation of $4-\mathrm{CP}$ then takes place according to scheme 1 , but two 
Table 3 Electrochemical peak parameters of the tested carbon electrodes resulting from the adsorption and cyclization (from the 75th $\mathrm{CV}$ ) in depolarizer solution

\begin{tabular}{lllll}
\hline Depolarizer: $2 \mathrm{mM}$ & 4-CP & & \\
\hline Samples & \multicolumn{2}{l}{ Peak parameters (potential/current) } & & \\
\cline { 2 - 5 } & \multicolumn{2}{l}{ Anodic $E_{\mathrm{a}} / i_{\mathrm{a}}\left(\mathrm{mV} / \mathrm{mA} \mathrm{g}^{-1}\right)$} & & Cathodic $E_{\mathrm{c}} / \mathrm{i}_{\mathrm{c}}\left(\mathrm{mV} / \mathrm{mA} \mathrm{g}^{-1}\right)$ \\
\cline { 2 - 5 } & $\mathrm{a} 1$ & $\mathrm{a} 2$ & $+30 / 13.4$ & $\mathrm{c} 2$ \\
\hline CB-B & $+630 / 12.4$ & - & $+210 / 3.4$ & - \\
CB-C & $+380 / 3.2$ & $+840 / 2.0$ & $+180 / 1.4$ & $+420 /-$ \\
G-SA & $+350 / 2.4$ & $+820 / 1.4$ & $+100 / 4.4$ & - \\
AC-1-HT & $+500 / 4.6$ & $+950 / 0.8$ & & -
\end{tabular}

Depolarizer: $2 \mathrm{mM}$ of 2,4-DCP

\begin{tabular}{|c|c|c|c|c|c|}
\hline & \multicolumn{5}{|c|}{ Peak parameters (potential/current) } \\
\hline & \multicolumn{3}{|c|}{ Anodic $E_{\mathrm{a}} / i_{\mathrm{a}}\left(\mathrm{mV} / \mathrm{mA} \mathrm{g}^{-1}\right)$} & \multicolumn{2}{|c|}{ Cathodic $E_{\mathrm{c}} / \mathrm{i}_{\mathrm{c}}\left(\mathrm{mV} / \mathrm{mA} \mathrm{g}^{-1}\right)$} \\
\hline & a1 & $\mathrm{a} 2$ & a3 & $\mathrm{c} 1$ & $\mathrm{c} 3$ \\
\hline CB-B & $+860 / 24$ & - & - & $-180 / 28$ & - \\
\hline $\mathrm{CB}-\mathrm{C}$ & $+420 / 4.0$ & $+840 / 1.0$ & $-50 / 1.5$ & $+150 / 5.0$ & $-240 /-$ \\
\hline G-SA & $+350 / 2.8$ & $+780 / 0.4$ & - & $+180 / 3.0$ & - \\
\hline AC-1-HT & $+520 / 3.6$ & $+920 /-$ & - & $+50 / 3.0$ & - \\
\hline \multicolumn{6}{|c|}{ Depolarizer: $0.5 \mathrm{mM}$ of $2,4,6-\mathrm{TCP}$} \\
\hline & \multicolumn{5}{|c|}{ Peak parameters (potential/current) } \\
\hline & \multicolumn{3}{|c|}{ Anodic $E_{\mathrm{c}} / \mathrm{i}_{\mathrm{c}}\left(\mathrm{mV} / \mathrm{mA} \mathrm{g}^{-1}\right)$} & \multicolumn{2}{|c|}{ Cathodic $E_{\mathrm{c}} / \mathrm{i}_{\mathrm{c}}\left(\mathrm{mV} / \mathrm{mA} \mathrm{g}^{-1}\right)$} \\
\hline & a1 & a2 & a3 & $\mathrm{c} 1$ & $\mathrm{c} 3$ \\
\hline CB-B & $+650 / 11.6$ & - & - & $-10 / 14.6$ & - \\
\hline $\mathrm{CB}-\mathrm{C}$ & $+410 / 2.6$ & $+770 / 0.8$ & $-0 / 1.2$ & $+210 / 2.8$ & $-240 /-$ \\
\hline G-SA & $+340 / 4.0$ & $+750 / 0.4$ & - & $+250 / 4.0$ & - \\
\hline AC-1-HT & $+450 / 3.2$ & $+800 /-$ & - & $+150 / 2.2$ & - \\
\hline
\end{tabular}

different pathways are possible for 2,4-DCP and 2,4,6-TCP. Degradation of 2,4DCP leads to the formation of similar amounts of 4-CP (except for AC-2 and AC-1HT). 2,4,6-TCP degrades to similar amounts of 2,4-DCP and 4-CP; only for CB-C and G-SA is the concentration of 4-CP higher (Fig. 4c; Table 2).

\section{Conclusion}

The type of carbon materials and its porosity plays a decisive part during the initial stages of CPs electrodegradation on powdered carbon electrodes. Of the three groups of carbons, high-surface ACs with micropore domination, mesoporous CB 
(CB-B) and low-surface graphitized materials, CB-B is the most efficient for electrodegradation. Its adsorption of CPs was nearly tenfold lower than that of ACs but had a similar double electric layer pseudo-capacity. The presence of Faradaic reactions was not masked by capacity currents, and the nearly fivefold greater faradaic peak currents recorded for this CB than for low-surface materials indicate that it is the most active in $\mathrm{CP}$ electrodegradation. This was confirmed by chromatographic analysis of the electrolyte solution after electrochemical action (CP electrodegradation products were present) and from an interpretation of the FTIR spectral changes in the carbon electrode materials (surface covered by CP electropolymerization products).

Acknowledgments This work was partially supported by Polish Ministry of Science and Higher Education (Project No. N N209 099037).

Open Access This article is distributed under the terms of the Creative Commons Attribution License which permits any use, distribution, and reproduction in any medium, provided the original author(s) and the source are credited.

\section{References}

1. Czaplicka M (2004) Sources and transformations of chlorophenols in the natural environment. Sci Total Environ 322:21-39

2. Boudenne J-L, Cerclier O (1999) Performance of carbon black-slurry electrodes for 4-chlorophenol oxidation. Water Res 33:494-504

3. Ureta-Zanartu MS, Bustos P, Berrios C, Diez MC, Mora ML, Gutierrez C (2002) Electrooxidation of 2,4-dichlorophenol and other polychlorinated phenols at a glassy carbon electrode. Electrochim Acta 47:2399-2406

4. Ureta-Zanartu MS, Mora ML, Diez MC, Berrios C, Ojeda J, Gutierrez C (2002) Chlorophenol electrooxidation on iron oxide-covered aluminosilicates deposited on glassy carbon. J Appl Electrochem 32:1211-1218

5. Sripriya R, Chandrasekaran M, Subramanian K, Asokan K, Noel M (2007) Electrochemical destruction of $p$-chlorophenol and $p$-nitrophenol-influence of surfactants and anode materials. Chemosphere 69:254-261

6. Berrios C, Arce R, Rezende MC, Ureta-Zanartu MS, Gutierrez C (2008) Electrooxidation of chlorophenols at a glassy carbon electrode in a pH 11 buffer. Electrochim Acta 53:2768-2775

7. Wang H, Wang JL (2008) The cooperative electrochemical oxidation of chlorophenols in anodecathode compartments. J Hazard Mater 154:44-50

8. Chen JL, Chiou G-C, Wu C-C (2010) Electrochemical oxidation of 4-chlorophenol with granular graphite electrodes. Desalination 264:92-96

9. Anandhakumar S, Chandrasekaran M, Noel M (2010) Anodic oxidation of chlorophenols in micelles and microemulsions on glassy carbon electrode: the medium effect on electroanalysis and electrochemical detoxification. J Appl Electrochem 40:303-310

10. Ureta-Zanartu MS, Bustos P, Diez MC, Mora ML, Gutierrez C (2001) Electro-oxidation of chlorophenols at a gold electrode. Electrochim Acta 46:2545-2551

11. Wang J, Li X (2012) Electrochemical treatment of wastewater containing chlorophenols using borondoped diamond film electrodes. J Cent South Univ 19:1946-1952

12. Torres RA, Torres W, Peringer P, Pulgarin C (2003) Electrochemical degradation of $p$-substituted phenols of industrial interest on $\mathrm{Pt}$ electrodes. Attempt of a structure-reactivity relationship assessment. Chemosphere 50:97-104

13. Fengbin L, Guangping H, Ming Z, Min Q, Lingjiao H (2011) Electrochemical behaviors of chlorophenol aqueous solutions at boron-doped diamond electrode. Open Mater Sci J 5:35-39 
14. Ežerskis Z, Jusus Z (2001) Electropolymerization of chlorinated phenols on a Pt electrode in alkaline solution. Part I: a cyclic voltammetry study. J Appl Electrochem 31:1117-1124

15. Pirvu C, Marcu M, Banu A (2010) Deactivation of gold electrode at chlorophenols electrooxidation. Rev Chim (Buchar) 61:585-589

16. Cañizares P, García-Gómez J, Sáez C, Rodrigo MA (2003) Electrochemical oxidation of several chlorophenols on diamond electrodes. Part I. Reaction mechanism. J Appl Electrochem 33:917-927

17. Agboola B, Nyokong T (2007) Electrocatalytic oxidation of chlorophenols by electropolymerised nickel(II) tetrakis benzylmercapto and dodecylmercapto metallophthalocyanines complexes on gold electrodes. Electrochim Acta 52:5039-5045

18. Coteiro RD, De Andrade AR (2007) Electrochemical oxidation of 4-chlorophenol and its by-products using $\mathrm{Ti} / \mathrm{Ru}_{0.3} \mathrm{M}_{0.7} \mathrm{O}_{2}(\mathrm{M}=\mathrm{Ti}$ or $\mathrm{Sn})$ anodes: preparation route versus degradation efficiency. $\mathrm{J}$ Appl Electrochem 37:691-698

19. Cheng IF, Fernando Q, Korte N (1997) Electrochemical dechlorination of 4-chlorophenol to phenol. Environ Sci Technol 31:1074-1078

20. Cheng H, Scott K, Christensen PA (2003) Electrochemical hydrodehalogenation of chlorinated phenols in aqueous solutions. I. Material aspects. J Electrochem Soc 150:D17-D24

21. Wen Q, Yang T, Wang S, Chen Y, Cong L, Qu Y (2013) Dechlorination of 4-chlorophenol to phenol in bioelectrochemical systems. J Hazard Mater 244-245:743-749

22. Zheng M, Bao J, Liao P, Wang K, Yuan S, Tong M, Long H (2012) Electrogeneration of $\mathrm{H}_{2}$ for Pdcatalytic hydrodechlorination of 2,4-dichlorophenol in groundwater. Chemosphere 87:1097-1104

23. Pakuła M, Swiątkowski A, Biniak S (1995) Electrochemical behaviour of modified activated carbons in aqueous and nonaqueous solutions. J Appl Electrochem 25:1038-1044

24. Pakuła M, Walczyk M, Biniak S, Świątkowski A (2007) Electrochemical and FTIR studies of the mutual influence of lead(II) or iron(III) and phenol on their adsorption from aqueous acid solution by modified activated carbons. Chemosphere 69:209-219

25. Biniak S, Swiatkowski A, Pakuła M, Sankowska M, Kuśmierek K, Trykowski G (2013) Cyclic voltammetric and FTIR studies of powdered carbon electrodes in the electrosorption of 4-chlorophenols from aqueous electrolytes. Carbon 51:301-312

26. Hamdaouia O, Naffrechoux E (2007) Modeling of adsorption isotherms of phenol and chlorophenols onto granular activated carbon. Part I. Two-parameter models and equations allowing determination of thermodynamic parameters. J Hazard Mater 147:381-394

27. Lorenc-Grabowska E, Gryglewicz G, Machnikowski J (2010) p-Chlorophenol adsorption on activated carbons with basic surface properties. Appl Surf Sci 256:4480-4487

28. Błażewicz S, Biniak S, Pakuła M, Świątkowski A, Bystrzejewski M (2010) Influence of hightemperature treatment of granular activated carbon on its structure and electrochemical behavior in aqueous electrolyte solution. J Mater Res 25:1617-1628

29. Ežerskis Z, Jusus Z (2002) Electropolymerization of chlorinated phenols on a Pt electrode in alkaline solution. Part III: a Fourier transformed infrared spectroscopy study. J Appl Electrochem 32:755-762

30. Pakuła M, Świątkowski A, Walczyk M, Biniak S (2005) Voltammetric and FT-IR studies of modified activated carbon systems with phenol, 4-chlorophenol or 1,4-benzoquinone adsorbed from aqueous electrolyte solutions. Colloids Surf A 60:145-155

31. Terashima C, Rao TN, Sarada BV, Tryk DA, Fujishima A (2002) Electrochemical oxidation of chlorophenols at a boron-doped diamond electrode and their determination by high-performance liquid chromatography with amperometric detection. Anal Chem 74:895-902

32. Wang H, Wang J (2009) Comparative study on electrochemical degradation of 2,4-dichlorophenol by different Pd/C gas-diffusion cathodes. Appl Catal B 89:111-117

33. Chen J-L, Wang J-Y, Wu C-C, Chiang K-Y (2011) Electrocatalytic degradation of 2,4-dichlorophenol by granular graphite electrodes. Colloids Surf A 79:163-168

34. Khene S, Nyokong T (2011) Electrooxidation of chlorophenols catalyzed by nickel octadecylphthalocyanine adsorbed on single-walled carbon nanotubes. Electroanalysis 23:1901-1911 